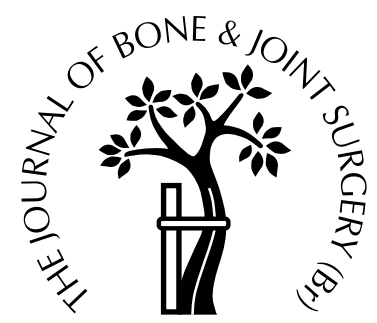

\title{
Functional outcome after open supracondylar fractures of the humerus
}

\author{
THE EFFECT OF THE SURGICAL APPROACH \\ Michael D. McKee, Justin Kim, Khaled Kebaish, \\ David J. G. Stephen, Hans J. Kreder, Emil H. Schemitsch \\ From the University of Toronto, Canada
}

W e reviewed 26 patients who had had internal fixation of an open intra-articular supracondylar fracture of the humerus. All operations were performed using a posterior approach, 13 with a triceps split and 13 with an olecranon osteotomy. The outcome was assessed by means of the Mayo Elbow score, the Disability of the Arm, Shoulder and Hand (DASH) score and the SF-36 Physical Function score. Patients with an olecranon osteotomy had less good results.

J Bone Joint Surg [Br] 2000;82-B:646-51.

Received 2 August 1999; Accepted after revision 13 December 1999

Open intra-articular fractures of the distal humerus are high-energy injuries which are often comminuted and associated with extensive soft-tissue damage. They are very difficult to treat. ${ }^{1-4}$ Anatomical reduction, rigid fixation and immediate mobilisation give the best functional outcome. $^{5-11}$ In view of the high reported rate of infection, however, delayed fixation may be recommended. Grant et $\mathrm{al}^{1}$ found infection in $28 \%$ after fixation of open fractures of the distal humerus. In a series of open fractures of the humerus, half of which were distal or supracondylar, Mostafavi and Tornetta ${ }^{4}$ recommended treatment by external fixation. They had an incidence of pin-track infection of $44 \%$. Although many series include a small percentage of open injuries, there is little information regarding early fixation of open fractures of the distal humerus. $6,12,13$

M. D. McKee, MD, FRCS C, Assistant Professor, Upper Extremity Reconstructive Service

J. Kim, BSc, Research Student, Upper Extremity Reconstructive Service

K. Kebaish, MD, FRCS C, Orthopaedic Resident

E. H. Schemitsch, MD, FRCS C, Assistant Professor

Division of Orthopaedics, Department of Surgery, St Michael's Hospital, University of Toronto, Toronto, Ontario, Canada.

D. J. G. Stephen, MD, FRCS C, Assistant Professor

H. J. Kreder, MD, FRCS C, Assistant Professor

Division of Orthopaedics, Department of Surgery

Sunnybrook Health Sciences Centre, 2075 Bayview Avenue, Toronto,

Ontario, Canada M1R 2J3.

Correspondence should be sent to Dr M. D. McKee at 55 Queen Street East, Suite 800, Toronto, Ontario, Canada M5C 1R6.

(C)2000 British Editorial Society of Bone and Joint Surgery

0301-620X/00/510423\$2.00

646
We used one of two posterior approaches to the site of the fracture, either a triceps split or an olecranon osteotomy. Wilson et $\mathrm{al}^{14}$ reported no differences in functional outcome after treatment of closed intra-articular fractures of the distal humerus through either of these approaches. When the injuries are complicated by an open wound, it is typically posterior, caused by protrusion of the shaft of the humerus through the triceps and skin. It seems logical that incorporating the defect in the triceps into the surgical approach may involve less trauma and give a better functional outcome than compromising the extensor mechanism further by performing an olecranon osteotomy.

Even with rigid fixation and early mobilisation open fractures have a worse outcome than those with closed injuries of a similar pattern. ${ }^{3}$ We have therefore attempted to determine the effect of the surgical approach on the outcome after early fixation.

\section{Patients and Methods}

Between 1981 and 1998 we treated 36 patients with open intra-articular fractures of the distal humerus. At the time of review two had died, three would not participate and five were lost to follow-up, leaving 26 in the study, with a mean follow-up of 51 months (10 to $14^{1}$ ) after injury. There were 22 men and four women with a mean age of 44.4 years (17 to 78). All injuries were unilateral; 14 were of the right arm and 12 of the left; 17 were in the dominant and nine in the non-dominant arm. Nine patients had other fractures, and three had an associated palsy of the ulnar nerve. The causes of the injury were falls in 14 patients, bicycle accidents in five, motor-vehicle accidents in five and other causes in two. The AO types ${ }^{15}$ were $\mathrm{C} 1$ in five, $\mathrm{C} 2$ in 13 and $\mathrm{C} 3$ in eight. According to the classification of Gustilo and Anderson ${ }^{16}$ there were 13 grade-I, nine grade-II and four gradeIII open injuries.

The patients' health and elbow function were evaluated using three outcome measures: 1) a general health-status measure of the medical outcome, the short-form 36 (SF$36),{ }^{17}$ 2) a limb-specific patient-orientated score, the Disabilities of Arm, Shoulder and Hand (DASH) ${ }^{18,19}$ score; and 3) a surgeon-orientated assessment, the Mayo Elbow score. ${ }^{20}$ The SF-36 measures patients' self-perceived general level of health and has been used extensively to evaluate 
orthopaedic patients. ${ }^{17,21}$ The DASH is a limb-specific tool for outcome measurement which objectively records the function of the upper arm from the patients' perspective ${ }^{18,19}$ and deals particularly with difficulties in recreational pursuits or work which may not be reflected in problems encountered in activities of daily living. The Mayo Elbow score is a well-recognised outcome measure. ${ }^{20}$

Radiological assessment. Union was defined as bony bridging seen across three of four cortices at the site of the fracture on the anteroposterior and lateral radiographs. The degree of post-traumatic degenerative change was evaluated on the follow-up radiographs. As there is no described grading system for post-traumatic degenerative changes of the elbow, we used the scale of Knirk and Jupiter $^{22}$ which was originally designed for intra-articular fractures of the distal radius. Varus, valgus and recurvatum were also recorded.

Operative techniques. The mean time from injury to surgery was 27.9 hours with a median of 6.5 hours (2.9 to 192). Four patients with a delay of more than 24 hours had been referred from other hospitals; excluding these, the mean time from injury to surgery was 6.7 hours.

All patients received preoperative intravenous antibiotics. Patients were positioned in the lateral decubitus position with the affected side up. Under tourniquet control, a posterior approach was used and a thorough debridement performed, excising the edge of the traumatic wound and any devitalised soft tissue. Most free bony fragments were discarded, unless a significant portion of the joint surface was involved. Irrigation was carried out with a minimum of ten litres of sterile saline. Typically, a large tear was found in the triceps muscle/tendon. We used either a chevron-type olecranon osteotomy or a triceps-split approach ${ }^{14}$ (Fig. 1). In 20 injuries fixation was with two plates, a combination of precontoured plates, ${ }^{23} 3.5 \mathrm{~mm}$ dynamic compression plates, and $3.5 \mathrm{~mm}$ reconstruction plates, while six were fixed with a single plate on one column of the humerus with lag screws alone on the opposite side.

Postoperative management included prophylactic intravenous antibiotics for 48 hours and a posterior splint for seven to ten days. Active movement began when a removable resting splint was applied. Active or resisted extension was avoided for six weeks. The same programme of rehabilitation was used in both groups.

Statistical analysis. We compared the groups using a twotailed Student $t$-test; ( $\mathrm{p}<0.05$ was considered significant). The correlations between various categories were investigated using the Pearson product-moment correlation coefficient (r). Values less than 0.25 indicated a weak correlation, between 0.25 and 0.50 mild, between 0.50 and 0.75 moderate and more than 0.75 good. $^{19}$

\section{Results}

Table I gives the SF-36, DASH and Mayo Elbow scores. There were no statistically significant differences between the mean scores of men and women for all outcome measures. Age, gender, mechanism of injury, grade of open wound and type of fracture $(\mathrm{C} / 1 / 2 / 3)$ had no influence on outcome. The mean Mayo Elbow score was 79 (52 to 100). There were eight excellent, seven good, eight fair and three poor results.

The mean range of flexion-extension of the elbow was $97^{\circ}$ (55 to 140). One patient with an ipsilateral injury of the forearm lost $40^{\circ}$ of forearm rotation, but this remained normal in the remainder.

Comparison of the SF-36 scores with the US national averages showed significant differences between the physical function $(\mathrm{p}=0.01)$ and role physical $(\mathrm{p}=0.002)$ scores (Fig. 2). There were no other significant differences in the other categories. ${ }^{17}$ The mean DASH score was 23.7 (0 to 57.5) indicating minimal to moderate disability. A DASH score of 0 indicates normal, pain-free function and a score of 100 complete disability. The scores were normally distributed.

The optional module was answered by 19 patients. The mean score of the optional module was 44.1 (0 to 100). This indicates increased difficulty in aspects of daily living and in performing work-related tasks, sports, or other recreational pursuits. $^{18}$

Radiological examination. Restoration of bony anatomy was assessed from the postoperative radiographs. The mean immediate postoperative angulation was $2.5^{\circ}$ of varus/ valgus and $3.3^{\circ}$ of recurvatum. The mean postoperative step or gap in the articular surface was $1.4 \mathrm{~mm}$. The mean time to union was 14 weeks (6 to 55). Four patients had delayed union ( $>16$ weeks) at the metaphyseal-diaphyseal fracture line. In two of these union occurred uneventfully but two required autogenous bone grafting.

The degree of post-traumatic degenerative change was evaluated according to the scale of Knirk and Jupiter. ${ }^{22}$ There were 16 grade- 0 , five grade- 1 , three grade- 2 and two grade- 3 elbows. ${ }^{22}$ The type of approach had no effect on the quality of reduction or degree of post-traumatic degenerative change. Patients with grade- 2 or grade- 3 posttraumatic arthritic changes had lower Mayo Elbow scores $(p=0.03)$ and higher DASH scores $(p=0.04)$ than those with grade- 0 or grade- 1 change.

Associated injury. Patients with associated injuries had lower SF-36 scores in physical function (with, 62; without, $78 ; \mathrm{p}=0.08$ ), but this was not statistically significant. There were no other differences in any of the other categories. There were no significant differences between these two groups with regard to DASH scores (with, 22; without, 24; $\mathrm{p}=0.79$ ), Mayo Elbow scores (with, 78; without, 80; $\mathrm{p}=0.73$ ), or range of movement (with, $95^{\circ}$; without, $9^{\circ}$; $\mathrm{p}=0.72$ ).

Triceps split approach versus olecranon osteotomy. Although their demographic details were similar (Table II), patients who had the triceps-split approach had a statistically better outcome in the Mayo Elbow scores, the DASH optional module scores and the role-physical and 


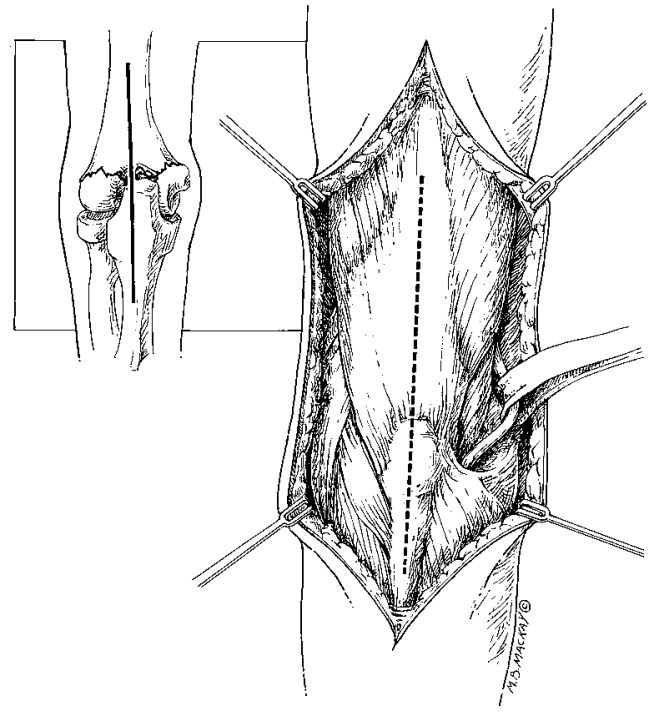

Fig. 1a

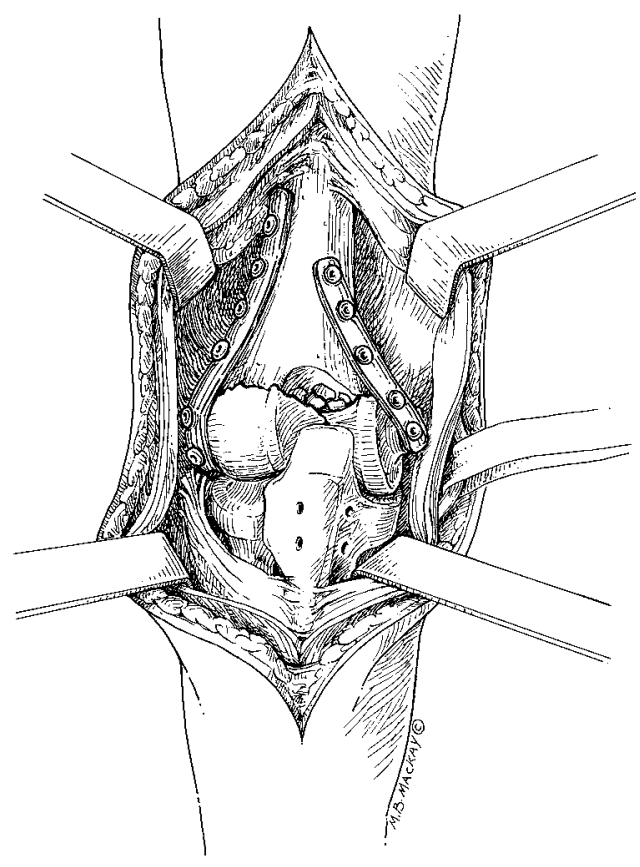

Fig. 1c

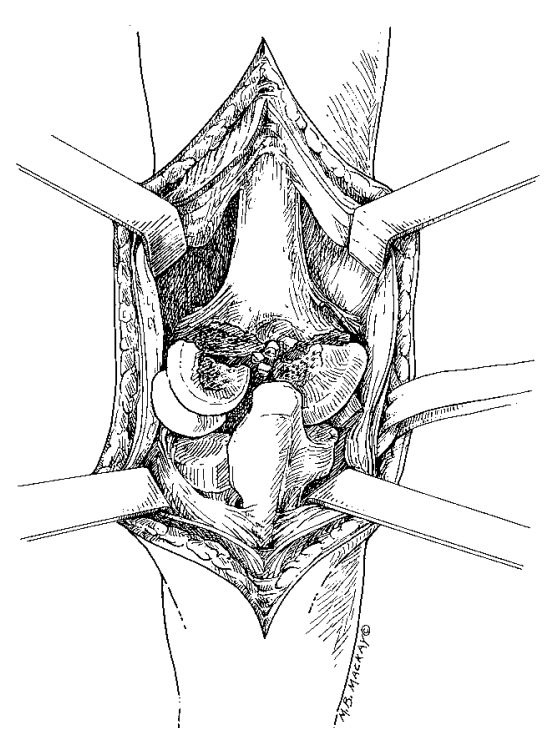

Fig. 1b

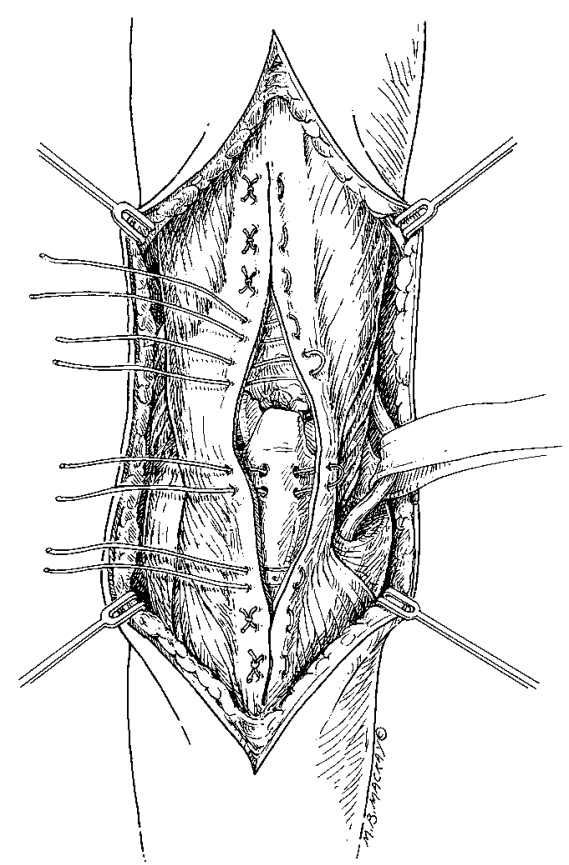

Fig. 1d

Figure 1a - Diagram showing the posterior view of the left elbow after a skin incision and subcutaneous dissection. The dotted line represents the planned incision through the triceps muscle and tendon. The ulnar nerve is identified and protected throughout by a Penrose drain. Figure $1 \mathrm{~b}$ - Diagram shows exposure of the site of the fracture after midline split of the triceps muscle and tendon. It is important to reflect the tendon sharply off the olecranon, preserving a contiguous layer medially and laterally to be reattached at the conclusion of the procedure. Visualisation of the anterior aspect of the joint can be improved by flexing the elbow and/or grasping the olecranon with a towel clip and pulling posteriorly. Figure $1 \mathrm{c}$ - Diagram showing a posterior view of the elbow after fixation of a bicolumnar, intra-articular fracture of the distal humerus with plates on both the medial and lateral columns. Drill holes have been placed through the olecranon for reattachment of the triceps. At this point the range of elbow movement and reduction of the fracture can be assessed. Since the olecranon is still intact, any narrowing of the trochlear groove through over compression of a comminuted fracture can be readily determined by extending the elbow and observing the olecranon/trochlear articulation. Figure 1d - Diagram showing closure of the triceps split with interrupted sutures, including some placed through drill holes in the olecranon.

bodily-pain scores of the SF-36 $(\mathrm{p}=0.05, \mathrm{p}=0.05$, $\mathrm{p}=0.04$ and $\mathrm{p}=0.002$, respectively). Although statistically not significant, patients with the triceps-split approach had a greater range of movement (Fig. 3).

Complications. Two patients developed a superficial infection but did not require further surgery and recovered after treatment with antibiotics. One patient with a grade-3 open injury developed a deep infection which required multiple debridements followed by implants of antibiotic beads and bone grafting to achieve union. The overall rate of infection was $11 \%$ (3 of 26). One case of iatrogenic palsy of the radial nerve resolved spontaneously. The over- 
Table I. Details of the outcome including the SF-36, DASH, and Mayo Elbow scores

\begin{tabular}{lcccc}
\hline & Minimum & Median & Maximum & Mean \pm SEM \\
\hline Length of follow-up (months) & 10 & 47.5 & 141.0 & $51 \pm 33$ \\
Arc length at final follow-up (degrees) & 55 & 100 & 140 & $97 \pm 22$ \\
Postop angulation (degrees) & 0.0 & 0.0 & 10.0 & $2.9 \pm 4.2$ \\
Postop step/gap (mm) & 0.0 & 0.0 & 12.0 & $1.4 \pm 2.5$ \\
SF-36 score* & & & & \\
PF & 20.0 & 77.5 & 100.0 & $73 \pm 23$ \\
RP & 0.0 & 100.0 & 100.0 & $61 \pm 47$ \\
BP & 31.0 & 74.0 & 100.0 & $70 \pm 24$ \\
GH & 10.0 & 77.0 & 100.0 & $71 \pm 24$ \\
VT & 10.0 & 65.0 & 86.7 & $62 \pm 20$ \\
SF & 0.0 & 90.0 & 100.0 & $81 \pm 26$ \\
RE & 0.0 & 100.0 & 100.0 & $72 \pm 36$ \\
MH & 4.0 & 74.0 & 100.0 & $73 \pm 20$ \\
DASH $\dagger$ (n=26) & 0.0 & 22.5 & 57.5 & $23.7 \pm 16.8$ \\
DASH optional module (n= 19) & 0.0 & 31.3 & 100.0 & $44.1 \pm 38.2$ \\
Mayo Elbow Score $\dagger$ & 52 & 80 & 100 & $79 \pm 14$ \\
\hline
\end{tabular}

* PF, physical function; RP, role physical; BP, bodily pain; GH, general health; VT, vitality; SF, social function; RE, role emotional; MH, Mental health. All scores are out of 100 .

$\dagger 0$ is the best possible outcome and 100 is the worst

$\ddagger 100$ is the best outcome

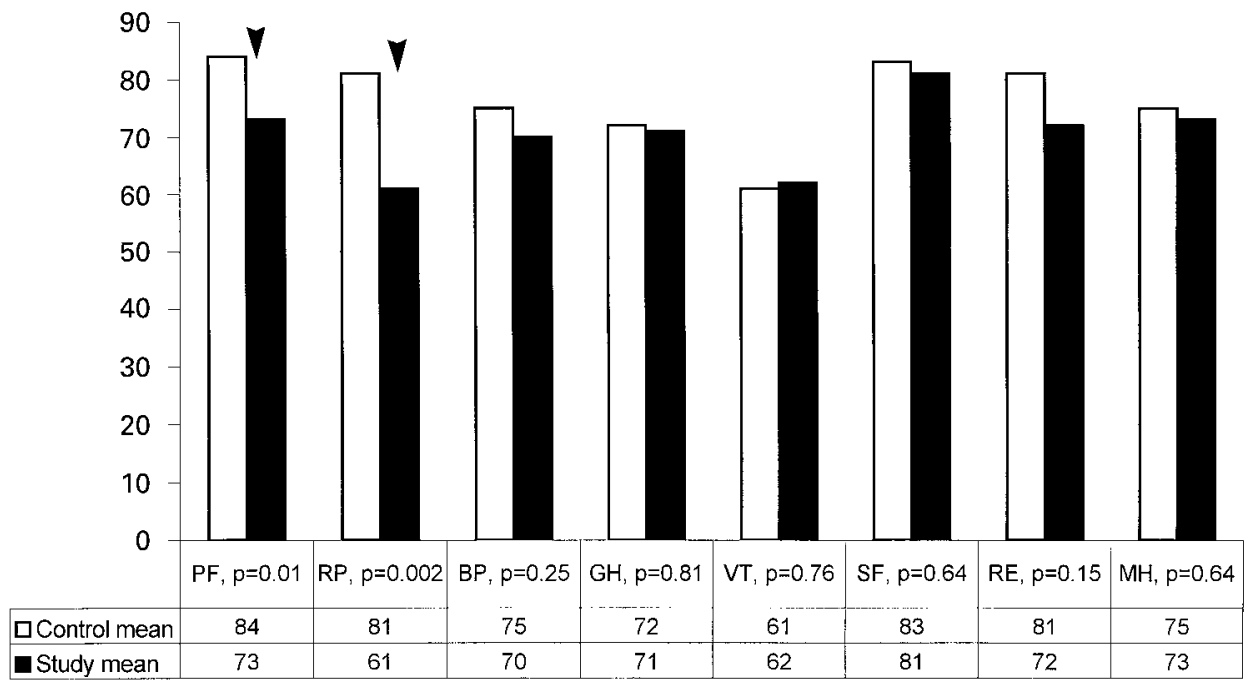

Fig. 2

SF-36 data comparing published control values with study values.

all rate of complications was $31 \%$ (8 of 26). The incidence of complications requiring further surgery was $11 \%$ (3 of 26). Three patients from the triceps-split group and five from the olecranon group developed a complication which had a detrimental effect on Mayo Elbow scores $(\mathrm{p}=0.01)$ and DASH scores $(\mathrm{p}=0.02)$. Two patients in the osteotomy group had removal of prominent metal used to fix the osteotomy.

\section{Discussion}

There is a very high incidence of bony and soft-tissue complications after open intra-articular fractures. ${ }^{3}$ No previous reports of the outcome of open reduction and internal fixation of open fractures of the distal humerus have been published, perhaps because of the rarity of the injury.

The preferred surgical exposure for the fixation of intra-
Table II. Details of the two groups

\begin{tabular}{llll}
\hline & $\begin{array}{l}\text { Olecranon group } \\
(\mathbf{n = 1 3})\end{array}$ & $\begin{array}{l}\text { Triceps group } \\
(\mathbf{n = 1 3})\end{array}$ & p value \\
\hline Mean age in years & 42.4 & 46.4 & 0.43 \\
Male:female & $10: 3$ & $12: 1$ & 0.65 \\
Type-C fracture & 13 & 13 & N/A \\
Mechanism & 10 fall/MVA* & 9 fall/MVA* & 0.61 \\
Dominant limb & 8 & 9 & 0.65 \\
Grade-I open injury & 7 & 6 & 0.77 \\
Mean follow-up in months & 49 & 53 & 0.39 \\
Associated injuries & 5 & 4 & 0.61 \\
\hline * motor-vehicle accident & & &
\end{tabular}

articular fractures of the distal humerus is posterior; and the extensor mechanism must be reflected. ${ }^{24,25}$ The conventional olecranon osteotomy provides a wide exposure but has considerable disadvantages such as added surgical time, delayed or nonunion, and local irritation caused by the fixation. ${ }^{25,26}$ Triceps-splitting procedures are simpler to per- 


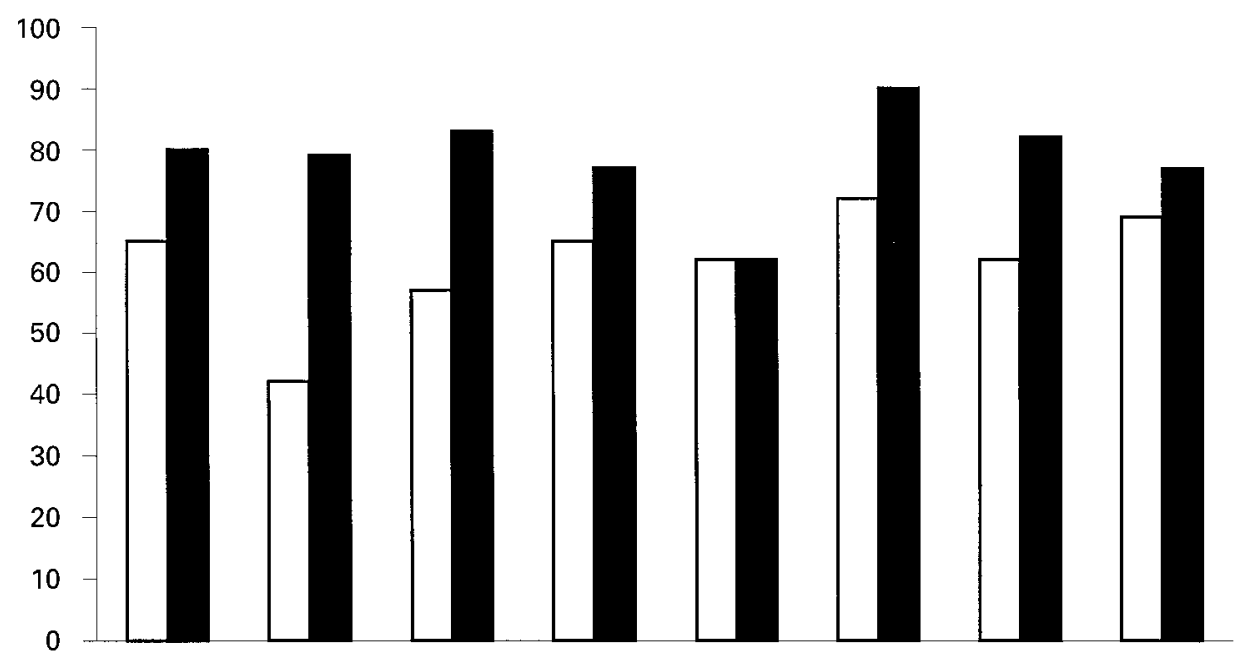

\begin{tabular}{|c|c|c|c|c|c|c|c|c|}
\hline & $P F, p=0.10$ & $R P, p=0.04$ & $B P, p=0.002$ & $\mathrm{GH}, \mathrm{p}=0.21$ & $V T, p=0.96$ & $S F, p=0.66$ & RE, $p=0.15$ & $\mathrm{MH}, \mathrm{p}=0.28$ \\
\hline 口Transolecranon approach & 65 & 42 & 57 & 65 & 62 & 72 & 62 & 69 \\
\hline Triceps split approach & 80 & 79 & 83 & 77 & 62 & 90 & 82 & 77 \\
\hline
\end{tabular}

Fig. 3a

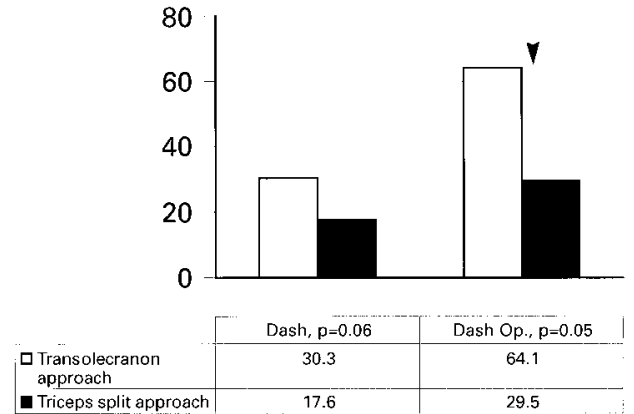

Fig. $3 b$

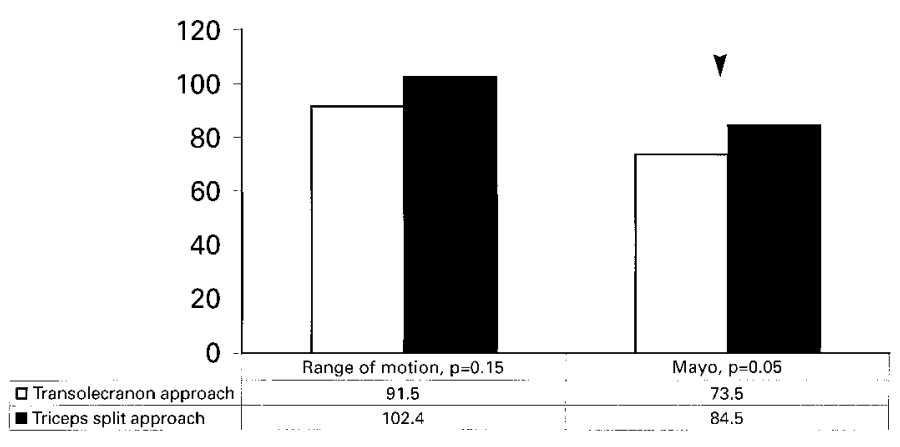

Fig. 3c

Comparison of patients who had a triceps-splitting approach with those who had an olecranon osteotomy showing a) the SF-36 score, b) the DASH score and c) the Mayo Elbow Performance scores and the total arc of movement.

form but critics suggest that they offer a limited exposure and the possibility of postoperative dehiscence. ${ }^{27}$ We have previously suggested that while the rate of reoperation in patients who had olecranon osteotomy was higher because of subsequent removal of metal, the quality of reduction, subjective outcome and objective muscle strength were similar to those who had a triceps-splitting approach. ${ }^{14}$

In our series, the soft-tissue wound was typically posterior and associated with a large tear in the triceps at the level of the metaphyseal/diaphyseal fracture. This defect is produced by the shaft of the humerus as it protrudes while the elbow flexes. This is different from similar injuries in children in which the shaft of the humerus protrudes anteriorly after a hyperextension injury and the anterior structures are damaged. ${ }^{27}$

It would seem appropriate to incorporate any traumatically-induced disruption of the extensor mechanism into the surgical approach for fixation of the fracture. For instance, if an intra-articular fracture of the distal humerus had an associated fracture of the olecranon, the extensor mechanism could be reflected proximally, the distal fracture fixed and the olecranon then repaired. Considerable disruption of the triceps, however, is more common, as seen in our series. We feel strongly that debriding this defect, extending it and then repairing it at the conclusion of the procedure is preferable to disrupting the extensor mechanism again by performing an olecranon osteotomy. The use of a triceps-splitting approach did not affect the quality of the reduction, but local irritation over the elbow from implanted metal used to fix the osteotomy was common.

There is a significant rate of infection after immediate fixation of open fractures. A previous report ${ }^{1}$ has described a high rate of deep infection of $28 \%$ after immediate fixation of open fractures of the distal humerus, but $45 \%$ of the fractures in this series were grade-III injuries which are 
associated with a higher rate of infection. Mostafavi and Tornetta ${ }^{4}$ recommended the use of an external fixator for open-shaft and supracondylar fractures, primarily caused by gunshot wounds, but they reported a rate of pin-track infection of $44 \%$. In our series infection was low despite a median time to surgery of over six hours and only one patient required reoperation for this reason. Although the intra-articular portion of the fracture usually healed uneventfully, other complications included delayed union of the metaphyseal/diaphyseal fracture line and bone grafting to obtain union in two patients.

Considering the severity of the injury, the functional outcome in our series, as measured by general health, limb-specific, surgeon-based and radiological outcome measures, was good. The SF-36 scores showed decreases in two of the 'physical' categories compared with population controls, but were otherwise within normal limits. The DASH scores showed a mean of 23.7, indicating mild to moderate disability, ${ }^{9}$ and the mean Mayo Elbow score was 79 , with only three patients having a poor result. The mean arc of movement in the flexion-extension plane was $97^{\circ}$, which corresponds to a 'functional' range for most individuals. $^{21}$

The limitations of our study include its retrospective nature, the relatively small numbers and a lack of objective testing of muscle strength. Since patients were not randomised to one surgical treatment or another, it is possible that surgeon bias is responsible for the differences seen between the groups. One group of surgeons, however, always used the triceps-split approach, and the other the olecranon osteotomy, so that the clinical details and severity of injury between the two groups were similar (Table II). Our previous studies with similar closed injuries has suggested that the strength of extension of the elbow and the outcome are similar after a triceps-split approach when compared with an olecranon osteotomy. Thus, if the outcome was surgeondependent, a similar difference would have been expected in the closed injuries, but this was not seen.

Our findings suggest that immediate open reduction and internal fixation of open, intra-articular fractures of the distal humerus is a safe and effective technique with a low rate of complications, good limb-specific outcome and reliable restoration of the status of the general health. Patients whose fractures were fixed by a triceps-splitting approach, incorporating any traumatic defects in the triceps into the approach, had improved limb-specific and pain scores compared with those who had a more conventional olecranon osteotomy.

No benefits in any form have been received or will be received from a commercial party related directly or indirectly to the subject of this article.

\section{References}

1. Grant SD, Gorczyca JT, Pugh KJ. Open distal humeral fractures. Proc Annual Orthopaedic Trauma Association Meeting Boston, 1996:269.
2. McKee MD, Jupiter JB. A contemporary approach to the management of complex fractures of the distal humerus and their sequelae. Hand Clin 1994;10:479-94.

3. McKee MD, Mehne DK, Jupiter JB. Part II. Fractures of the distal humerus. In: Browner, Jupiter, Levine, Trafton, eds. Skeletal trauma. Philadelphia: W. B. Saunders Co, 1998:1483-522.

4. Mostafavi HR, Tornetta P III. Open fractures of the humerus treated with external fixation. Clin Orthop 1997;337:187-97.

5. Zagorski JB, Jennings JJ, Burkhalter WE, Uribe JW. Comminuted intra-articular fractures of the distal humeral condyles: surgical vs nonsurgical treatment. Clin Orthop 1986;202:197-204.

6. Waddell JP, Hatch J, Richards RR. Supracondylar fractures of the humerus: results of surgical treatment. J Trauma 1988;28:1615-21.

7. Holdsworth BJ, Mossad MM. Fractures of the adult distal humerus: elbow function after internal fixation. J Bone Joint Surg $[\mathrm{Br}]$ 1990;72-B:362-5.

8. Gabel GT, Hanson G, Bennett JB, Noble PC, Tullos HS. Intraarticular fractures of the distal humerus in the adult. Clin Orthop 1987;216:99-108.

9. Horne G. Supracondylar fractures of the humerus in adults. J Trauma 1980;20:71-4.

10. Wildburger R, Mahring M, Hofer HP. Supraintercondylar fractures of the distal humerus: results of internal fixation. J Orthop Trauma 1991;5:301-7.

11. Schemitsch EH, Tencer AF, Henley MB. Biomechanical evaluation of methods of internal fixation of the distal humerus. J Orthop Trauma 1994;8:468-75.

12. Jupiter JB, Neff U, Holzach P, Allgower M. Intercondylar fractures of the humerus. J Bone Joint Surg [Am] 1985;67-A:226-39.

13. Jupiter JB. Complex fractures of the distal part of the humerus and associated complications. J Bone Joint Surg [Am] 1994;76-A:125264.

14. Wilson TL, Winston L, Richards RR, Schemitsch EH, McKee MD. Elbow extension strength following treatment of intraarticular distal humeral fractures: a comparison of triceps splitting versus olecranon osteotomy. Proc 53rd Annual Canadian Orthopaedics Associating meeting, 1998:148.

15. Mueller ME, Allgoewer M, Schneider R, Willenegger H. Manual of internal fixation. Edition 2. New York, Springer-Verlag, 1979.

16. Gustilo RB, Anderson JT. Prevention of infection in the treatment of one thousand and twenty-five open fractures of long bones. $J$ Bone Joint Surg [Am] 1976;58-A:453.

17. Ware JE, Snow KK, Kosinski M, Gandek B. SF-36 Health Survey Manual and Interpretation Guide. Boston, MA: New England Medical Center, The Health Institute, 1993.

18. Hudak PL, Amadio PC, Bombardier C. Development of an upper extremity outcome measure: the DASH (Disabilities of the Arm, Shoulder and Hand): the upper extremity collaborative group. Am J Ind Med 1996;29:602-8.

19. Turchin D, Beaton DE, Richards RR. Validity of observer-based aggregate scoring systems as descriptors of elbow pain, function and disability. J Bone Joint Surg [Am] 1998;80-A:154-62.

20. Otsuka NY, McKee MD, Liew A, et al. The effect of comorbidity and duration of nonunion on outcome after surgical treatment for nonunion of the humerus. J Shoulder Elbow Surg 1998;7:127-33.

21. Morrey BF, An KN, Chao EYS. Functional evaluation of the elbow. In: Morrey BF, ed. The elbow and its disorders. Philadelphia: W. B. Saunders, 1993;2:86-92.

22. Knirk JL, Jupiter JB. Intra-articular fractures of the distal end of the radius in young adults. J Bone Joint Surg [Am] 1986;68-A:647-59.

23. Lecestre P, Dupont JY, Lortat Jacob A, Ramadier JO. Les fractures complexes de l'extrèmetè infèrieure de l'humèrus chez l'adulte. Rev Chir Orthop 1979;65:11-23.

24. Bass RL, Stern PJ. Elbow and forearm anatomy and surgical approaches. Hand Clin 1994;10:343-56.

25. Bryan RS, Morrey BF. Extensive posterior exposure of the elbow: a triceps-sparing approach. Clin Orthop 1982;166:188-92.

26. Macko D, Szabo RM. Complications of tension-band wiring of olecranon fractures. J Bone Joint Surg [Am] 1985;67-A:1396-401.

27. Kasser JR, Richards K, Millis M. The triceps-dividing approach to open reduction of complex distal humeral fractures in adolescents: a cybex evaluation of triceps function and motion. J Paed Orthop 1990;10:93-6. 